DOI 10.5216/ia.v45i3.65079

\title{
POR UMA ESCOLA INTERCULTURAL: A SALA DE AULA COMO LUGAR DE MUITAS HISTÓRIAS
}

\author{
LUANA BARTH GOMES \\ CRISTINE GABriela de CAMPOS Flores \\ GILBERTO FerReIRA DA SILVA \\ Cledes Antonio CASAgrande \\ Universidade La Salle (UNILASALLE), Canoas, Rio Grande do Sul, Brasil
}

\begin{abstract}
Resumo: Este artigo aborda a temática da colonialidade na Educação Básica e tem como objetivo discutir a maneira como a escola brasileira tem participado na reprodução de uma única perspectiva histórica, a eurocêntrica. Para isso, estabelece um diálogo hermenêutico a partir de conceitos e reflexões de autores decoloniais, os quais defendem a produção de um pensamento desde o sul. Sugere-se a pedagogia decolonial como um dos caminhos para se chegar a outros conhecimentos, narrativas e cosmovisões. Tal dinâmica implica um diálogo crítico sobre os conhecimentos, modos de pensar do mundo ocidental e uma abertura aos povos originários e afrodiaspóricos em terras americanas. Por fim, defende-se a proposta de uma educação intercultural, que tenha como base a pluralidade e a ancestralidade de seus povos.
\end{abstract}

Palavras-chave: Colonialidade. Educação Decolonial. Educação Intercultural. Geoepistemologia.

"As histórias importam. Muitas histórias importam. As histórias foram usadas para espoliare caluniar, mas também podem ser usadas para empoderar e humanizar".

(ADICHIE, 2019, p. 32)

\section{INTRODUÇÃO}

Em algum momento de nossa trajetória escolar, ouvimos falar sobre a colonização. Nos explicaram que o processo de colonização acontece quando um país ou grupo de seres humanos ocupa novos territórios, com o objetivo de habitar novas terras e encontrar novas fontes de recursos. $O$ que dificilmente ouvimos é que esse processo não ocorreu de forma natural ou pacífica, pelo contrário, houve resistência e derramamento de sangue. A colonização foi um processo de invasão e apropriação. Os povos originários que habitavam as regiões colonizadas tinham sua própria forma de viver e pensar, de sentir e existir. Seus saberes e costumes foram subjugados e aqueles que sobreviveram à colonização, em muitos sentidos, foram obrigados a assumir a maneira de viver, pensar, sentir e existir do colonizador. Dizemos "em muitos sentidos", 
pois há povos que resistem, ainda hoje, a adotar totalmente o estilo de vida e o pensamento ocidental; há um fio condutor ancestral que os guia e lhes dá força para romper a barreira do silêncio e mostrar que existem outras formas de estar no mundo.

Embora nem sempre fique claro nas narrativas sobre a colonização, esse processo deixou feridas profundas nas regiões e nos povos que foram colonizados, mesmo após conquistarem a independência. Segundo Quijano (2002), as relações de dominação não encerraram após o fim do colonialismo, mas perduram até os dias atuais, em um fenômeno denominado por ele como colonialidade, reproduzido em três dimensões: a colonialidade do poder, do saber e do ser. O conceito de colonialidade denuncia a continuidade dos processos de colonização, que supostamente teriam sido superados. Percebemos, assim, a necessidade de uma profunda análise sobre a maneira como estamos, tradicionalmente, narrando os acontecimentos históricos e seus impactos nas comunidades e nos indivíduos que sofreram a horrível experiência da colonização.

Nesse sentido, no final dos anos 1990, um coletivo de intelectuais latinoamericanos, situados em diversas universidades das Américas, reuniu-se para formar o Grupo Modernidade e Colonialidade. Esse grupo iniciou um movimento para tensionar a herança colonial na América Latina a partir de pensadores do Sul e oferecer releituras históricas e problematizações para velhas e novas questões da América Latina, por meio da noção de "Giro decolonial", ou seja, de um "movimento de resistência teórico e prático, político e epistemológico, à lógica da colonialidade" (BALLESTRIN, 2013, p. 105).

No âmbito dessa discussão, Catherine Walsh conduz uma reflexão sobre os processos educacionais e propõe a perspectiva da interculturalidade crítica como base à pedagogia decolonial. Walsh (2005) defende a reconstrução de um pensamento críticooutro, que contempla o vivido e pensado desde a experiência da colonialidade, ou seja, um pensamento não baseado nos legados eurocêntricos, mas nos saberes do sul. Logo, a pedagogia decolonial oferece possibilidades para outros conhecimentos, narrativas e cosmovisões, num diálogo crítico com os conhecimentos e modos de pensar do mundo ocidental.

Este artigo se propõe a discutir a maneira como a escola brasileira tem participado na reprodução da perspectiva histórica eurocêntrica e defende a proposta de uma educação intercultural, que tenha como base a pluralidade e a ancestralidade de seu povo. Para tanto, utiliza-se a hermenêutica como abordagem metodológica. A discussão tem como pilares teóricos as elaborações do grupo Modernidade e Colonialidade, bem como publicações de escritores e intelectuais contemporâneos como Chimamanda Ngozi Adichie, Djamila Ribeiro, Grada Kilomba, Ailton Krenak, Daniel Munduruku e Linda Tuhiwai Smith.

Como estratégia, recorremos a uma arquitetura textual que toma como ponto de partida a construção reflexiva em torno da "história que nos contaram", procurando localizar elementos que auxiliem na compreensão de como se deu a construção do ideal do colonizador, herança que consolidou-se como "versão única e verdadeira" da história. Em um segundo momento, nos voltamos para um dar-se conta de que "continuamos a contar a história que nos foi contada". Finalmente exploramos e apostamos na importância da interculturalidade como possibilidade de diversificação das histórias 
GOMES, L. B.; FLORES, C. G. da S.; SILVA, G. F. da; CASAGRANDE, C. A.

presentes no território da escola e também como deslocamentos geoepistêmicos necessários para a (re)construção de conhecimentos outros, desde fontes diferenciadas da vertente oficial que nutriu hegemonicamente o avanço da ciência e do conhecimento em detrimento de outros modos de compreender nosso mundo.

\title{
A (ÚNICA) HISTÓRIA QUE NOS CONTARAM
}

Um dos teóricos do pensamento decolonial é Rodolfo Kusch ${ }^{2}$ (1922 - 1979). O pensamento filosófico de Kusch apresenta conceitos referencias para analisar narrativas construídas, entre eles destacamos os conceitos de "pequena história" e "grande história"3. A pequena história refere-se à narrativa e à perspectiva do colonizador europeu, é a história da elite, fala sobre o líder (herói); enquanto a grande história compreende diversas narrativas de comunidades e povos oprimidos, a vivência humana, a história real, a representação do todo e está relacionada à sobrevivência da espécie.

Um dos exemplos da prevalência da pequena história sobre a grande história pode ser visto na maneira como, tradicionalmente, a escola brasileira aborda a história do país. Apesar de algumas sociedades indígenas serem apresentadas nos livros didáticos, isso ocorre de forma genérica e estereotipada. Além disso, normalmente há uma lacuna temporal que suprime a forma como estas viviam antes da chegada do colonizador. Os povos originários aparecem na ocasião do "Descobrimento" ${ }^{4 \prime}$, em que é abordada a escravidão indígena e, em seguida, outra brecha de tempo se abre fazendo com que os ameríndios reapareçam somente quando se fala das Reduções Jesuíticas.

Daniel Munduruku ${ }^{5}$ é escritor indígena da etnia Munduruku. Em suas obras, o autor nos traz diversas narrativas e crônicas sobre suas experiências dentro e fora da aldeia. De acordo com Munduruku (2009, p. 24),

\begin{abstract}
Se quisermos pensar no "descobrimento", temos que negar a história dos que são nativos da terra. O termo "descobrimento" relaciona-se com a Europa e com todas as razões da colonização. Guarda silêncio sobre os fatores que levaram a Europa a explorar o Novo Mundo. Silencia a respeito dos conflitos entre portugueses e nativos e dos objetivos da colonização, baseados na expropriação territorial, na escravização e na destribalização.
\end{abstract}

O ensino a partir da pequena história, ou seja, da visão dos europeus, invisibiliza a história dos diferentes povos que compuseram e ainda compõem o Brasil. Referente à história do nosso país, Orlandi (1990, p. 66) também comenta que "o índio é totalmente excluído. No que se refere à identidade cultural, o índio não entra nem como estrangeiro, nem sequer como antepassado". Os povos indígenas aparecem na história do Brasil em flashes. São escolhidos determinados momentos para que apareçam, sem que comprometam a pequena história e sem tirarem o foco dos colonizadores europeus e dos catequizadores. Pouco se ensina sobre a origem dos povos indígenas na América, sua sobrevivência aos movimentos de colonização, às doenças e sua luta para serem vistos e reconhecidos pela sociedade como tais. Durante muitos anos essa era a história que aparecia nos livros didáticos. Nos últimos anos surgiu, aos poucos, uma tendência de apresentar alguns povos originários contemporâneos. Entretanto, ainda se mantêm essas lacunas que fazem o indígena aparecer e desaparecer da história brasileira. 
Outro exemplo é a Revolução Farroupilha (1835-1845), tão aclamada no estado do Rio Grande do Sul, fundada na pequena história, visto que omite partes importantes que envolvem outros povos. Os farroupilhas, na ocasião da guerra contra os federalistas, prometeram aos seus escravos que, se lutassem, seriam libertos. Porém não queriam precipitar o movimento abolicionista, então houve o Massacre de Porongos. Em uma noite, os Lanceiros Negros foram desarmados pelo General David Canabarro e dormiram separados do resto da tropa. Durante a madrugada, foram surpreendidos e mortos pelas tropas imperiais (SALAINl; CARVALHO, 2008).

Além desse episódio vergonhoso, o hino Rio-grandense ainda entoa frases que reforçam o racismo, como no trecho a seguir: "Mas não basta pra ser livre/Ser forte, aguerrido e bravo/Povo que não tem virtude/Acaba por ser escravo" (FONTOURA; MEDANHA, 1966). Entoá-lo sem a devida reflexão e contextualização da violência explícita que ele contém é o mesmo que negar ou concordar com o conteúdo discriminatório contido nos versos.

A história que a escola reproduz é eurocêntrica, gera silenciamentos, apagamentos e distorções dos demais povos que a compõem. Isso cria uma visão que distancia os educandos da diversidade que há no país, produzindo invisibilidades, reforçando estereótipos e contribuindo para a perpetuação de um sistema racista. Sobre isso, a escritora brasileira Djamila Ribeiro ${ }^{6}$ faz o seguinte comentário "quando criança fui ensinada que a população negra havia sido escrava e ponto, como se não tivesse existido uma vida anterior nas regiões onde essas pessoas foram tiradas à força" (RIBEIRO, 2019, p. 7 ) e afirma: "com o tempo, compreendi que a população negra havia sido escravizada, e não era escrava" (RIBEIRO, 2019, p. 8).

Nesse caminho, a autora Nigeriana Chimamanda Ngozi Adichie ${ }^{7}$ chama atenção para a forma como a literatura ocidental reproduz um pensamento estereotipado em relação ao continente Africano. Ao narrar suas percepções no período em que morou nos Estados Unidos, Adichie (2019, p. 18) revela:

[...] se eu não tivesse crescido na Nigéria e se tudo o que eu soubesse sobre a África viesse das imagens populares, também iria achar que se tratava de um lugar com paisagens maravilhosas, animais lindos e pessoas incompreensíveis travando guerras sem sentido, morrendo de pobreza e de aids, incapazes de falar por si mesmas e esperando para serem salvas por um estrangeiro branco e bondoso.

Adichie (2019) entende que a narrativa incompleta e empobrecida a respeito de um povo gera uma história única sobre ele, segundo a autora "mostre um povo como uma coisa, uma coisa só, sem parar, e é isso que esse povo se torna". Nesse sentido, compreende-se que à medida que se apresenta os povos indígenas ou africanos unicamente a partir da perspectiva ocidental eurocentrada, ocultamos a pluralidade de suas culturas, línguas, expressões religiosas, entre outros elementos que também compõem a cultura brasileira e são desconhecidos de grande parte da população.

De maneira semelhante, a pesquisadora maori Linda Tihuwai Smith ${ }^{8}$, da Nova Zelândia, é enfática em caracterizar um modo de pensar que predominou durante a 
GOMES, L. B.; FLORES, C. G. da S.; SILVA, G. F. da; CASAGRANDE, C. A.

colonização sobre os povos que viveram essa trágica e cruel experiência, como na passagem que vemos a seguir: "Não podíamos inventar coisas, não podíamos criar instituições nem história, não podíamos imaginar, não podíamos produzir nada de valor, não sabíamos usar a terra, nem outros recursos do mundo natural, não praticávamos as 'artes da civilização'" (SMITH, 2018, p. 38). A crueldade que resulta desse modo de pensar ajusta-se aos efeitos que se colhe no presente de uma ação histórica que se arrastou e ainda insiste em permanecer.

Conforme Smith (2018, p. 43),

\begin{abstract}
A negação das perspectivas indígenas sobre a história atendeu a uma necessidade imperiosa da ideologia colonial durante o seu processo impositivo. Tal negação se entende em parte porque tais perspectivas eram consideradas evidentemente 'primitivas' e 'incorretas'; contudo, mais fundamental ainda, porque elas desafiavam e resistiam à missão colonizadora.
\end{abstract}

As declarações de Ribeiro, Adichie e Smith evidenciam as marcas da colonialidade. É notável que as autoras sentem que suas histórias não estão representadas dentro da dita história "oficial", contada a partir da perspectiva do colonizador e conquistador, em um processo que expropria sujeitos e visões diferenciadas.

A pequena história, que conhecemos como história "oficial" e que continuamos a reproduzir, está relacionada à colonialidade de poder. Trata-se de uma narrativa elaborada pela civilização moderna que, ao se autodescrever como superior e desenvolvida, justificou sua "obrigação moral" em empreender um projeto educativo a fim de "civilizar os selvagens e bárbaros". A violência utilizada para com os povos que resistiram a esse processo civilizatório foi narrada como "inevitável" e interpretada como "compensatória" diante dos benefícios da modernização. A luta dos povos originários das regiões que sofreram o processo de colonização, no dizer de Smith (2018), evidencia a postura de afirmar e reclamar sua humanidade, algo que tem sido um fio condutor dos discursos anticoloniais a respeito da colonização e da opressão. É assim, por meio da pequena história da modernidade, que promete desenvolvimento e boa vida para todos, que a lógica da colonialidade se perpetua.

O projeto de modernidade está intimamente ligado à colonialidade. A construção de classificações sociais, tais como raça, gênero, orientação sexual e trabalho, por parte da colonialidade, é a base das relações de exploração e dominação que sustentam o capitalismo mundial colonial (QUIJANO, 2002). A lógica da colonialidade inclui "apropriação massiva da terra (e hoje dos recursos naturais), a massiva exploração do trabalho (da escravidão aberta do século dezesseis até o século dezenove, para a escravidão disfarçada até o século vinte e um) e a dispensabilidade de vidas humanas" (MIGNOLO, 2008, p. 293).

O Brasil, assim como os demais países colonizados, viveu o processo de invasão, conquista e colonização, tendo suas terras e suas gentes exploradas e saqueadas de diversas formas. Nas colônias, predominava a mão-de-obra escrava, baseada na exploração dos africanos trazidos à força. Durante anos a estrutura colonial trabalhou na construção do conceito de raça que subalterniza diversos grupos, entre eles africanos e 
indígenas, exaltando a branquitude e o eurocentrismo e fundando o capitalismo sobre as bases da exploração, da segregação.

Poderíamos citar diversos exemplos em que a pequena história prevaleceu na história do Brasil e do mundo, seja na exaltação da Princesa Isabel com a sua Lei Áurea', em que ela simplesmente cedeu à pressão vinda do exterior para que a escravidão fosse abolida, seja na aclamação de "heróis nacionais", em sua grande maioria brancos e do gênero masculino, entre tantos outros exemplos. Em 2019, a escola de samba Estação Primeira de Mangueira, do Rio de Janeiro, nos brindou com o samba-enredo "Histórias Para Ninar Gente Grande". Neste, há uma crítica às omissões e distorções existentes na história brasileira:

\begin{abstract}
Brasil, meu nego/Deixa eu te contar/A história que a história não conta/O avesso do mesmo lugar/Na luta é que a gente se encontra/Brasil, meu dengo/A Mangueira chegou/Com versos que o livro apagou/Desde 1500 tem mais invasão do que descobrimento/Tem sangue retinto pisado/Atrás do herói emoldurado/Mulheres, tamoios, mulatos/Eu quero um país que não está no retrato. (Samba-Enredo 2019 - Histórias Para Ninar Gente Grande - G.R.E.S. Estação Primeira de Mangueira).
\end{abstract}

Tais apagamentos e distorções, denunciados pelo samba-enredo, demonstram como continuamos a reproduzir a narrativa do colonizador, que extirpa da história a importância de diversos povos formadores do Brasil, que constituem não só a nossa cultura, mas nossa ancestralidade. Nesse caminho, Mignolo $(2008$, p. 293) explica que "a matriz racial de poder é um mecanismo pelo qual não somente as pessoas, mas as línguas e as religiões, conhecimentos e regiões do planeta sejam racializados". Além disso, o autor defende que a história é contada e os eventos são classificados a partir de uma lógica racista, que divide os seres humanos em superiores e inferiores. Essa estratégia de organização hierárquica cumpre o papel de deslocar a diversidade étnicocultural dos povos originários, das regiões colonizadas e dos povos diaspóricos, que foram vítimas do processo de escravização, para uma dinâmica que homogeneíza as diferenças em prol da assunção do binômio redutor colonizador-colonizado. De um lado instituiu-se a cultura do colonizador, como supremacia e modelo a ser seguido, e de outro a do colonizado.

Com essa mesma perspectiva, Adichie (2019) defende que nossos conhecimentos são formados pelas histórias que escutamos e alerta sobre os perigos de ouvirmos apenas um dos lados de uma mesma história, até porque, segundo a autora, as histórias são definidas pelo princípio do poder, "como elas são contadas, quem as conta, quando são contadas e quantas são contadas depende muito de poder" (ADICHIE, 2019, p. 23). Para Adichie (2019, p. 27), a história única "rouba a dignidade das pessoas. Torna difícil o reconhecimento da nossa humanidade em comum", ela reforça estereótipos, segrega e inferioriza quem não está dentro do "padrão" de quem contou a história.

Os estereótipos têm origem na pequena história e se perpetuam em razão dos interesses da colonialidade de poder. A visão construída dessa forma faz com que o indígena contemporâneo sofra críticas por viver em meio ao sistema capitalista, por 
GOMES, L. B.; FLORES, C. G. da S.; SILVA, G. F. da; CASAGRANDE, C. A.

estudar, por utilizar roupas, por se autoafirmar em sua diferença. Para o pensamento ocidental, os ameríndios deveriam permanecer estagnados no tempo, vivendo do mesmo modo que na ocasião da invasão europeia há 520 anos.

O mesmo pensamento também faz com que, mesmo passados 132 anos da abolição da escravatura, homens e mulheres negros tenham uma diferença salarial em relação a homens e mulheres brancos exercendo os mesmos cargos; produz uma naturalização de que haja poucas pessoas negras ocupando altos cargos em empresas e de que até poucos anos atrás, antes do advento das ações afirmativas, afrodescendentes pouco ocupavam as vagas das universidades públicas.

Ribeiro (2019) afirma que pessoas brancas não costumam pensar sobre o que significa pertencer à branquitude, pois o debate racial é sempre focado na negritude. De acordo com a autora, perceber-se é algo transformador. É o que permite situar nossos privilégios e nossas responsabilidades diante de injustiças contra grupos sociais vulneráveis.

Dessa maneira, entendemos a urgência em discutir e situar os diferentes lugares de fala no debate racial, assumindo que há privilégio para alguns grupos e opressão para outros. E, nesse caminho, a escola tem um papel determinante, pois somente quando existir esse entendimento pela maior parte da população existirá a possibilidade de criticarmos esse sistema e iniciarmos uma luta coletiva contra ele.

\section{A (ÚNICA) HISTÓRIA QUE CONTINUAMOS CONTANDO}

Os currículos das escolas brasileiras ainda estão pautados no eurocentrismo, embora haja mudanças significativas. O trabalho com outras culturas que não a ocidental acaba ocorrendo na ocasião das datas comemorativas, abordando as culturas indígenas e africanas de forma pontual e superficial. É muito comum que só se fale dos ameríndios no Dia do Índio e na data do "Descobrimento" do Brasil, assim como o trabalho sobre os africanos e afro-brasileiros fica isolado no Dia da Abolição da Escravatura e no Dia da Consciência Negra.

Os saberes selecionados como oficiais desconsideram a pluralidade dos povos indígenas e africanos, os inferiorizam e descaracterizam. Além de tudo, ainda relegam estes povos ao passado, a uma visão que generaliza suas características. Segundo Bonin (2008, p. 318):

\footnotetext{
Esse índio, objeto de conhecimento e celebração num espaço delimitado nos calendários escolares, é quase sempre amalgamado à natureza e reconhecido por atributos como alegria, ingenuidade, liberdade. Um efeito dessas representações é o estranhamento que nos causa o encontro com indígenas em contextos urbanos, participando de atividades comerciais, ou em noticiários que deixam ver, de relance e de modo fugaz, a situação de miséria e violência a que estão submetidos muitos povos indígenas na atualidade brasileira.
}

Para as crianças, as datas comemorativas como o Dia do Índio ou o Dia da Consciência Negra tornam-se uma festa, pois se pintam e se enfeitam com lindos cocares feitos de papel ou penas ou ainda fazem tranças e usam turbantes em alusão a 
penteados afros. Uma pintura vazia de significados que dá a ideia de que todas as etnias indígenas realizam essa prática, bem como um penteado descontextualizado que em nada aborda a cultura africana e afro-brasileira. O que se coloca aqui é a permanência de um modo de contar a história, a mesma que nos foi contada e que, de algum modo, insistimos em continuar contando. Efeito perverso daquilo que Mignolo (2007) nomina de colonialidade, esta espécie de manutenção do status e dos valores do colonizador, já em um grau de internalização de forma violenta assumida pelo colonizado. Mignolo (2007, p. 26) refere-se a isso como um processo histórico que se esconde sob a "retórica de la modernidad".

Observa-se então uma festa na qual os homenageados não são retratados do modo como realmente vivem, que muitas vezes exclui suas opiniões sobre o que pensam em relação às datas expressas no calendário escolar e que passam longe do que deveria ser o ensino da história e da cultura dos povos indígenas e dos afro-brasileiros. $\mathrm{O}$ trabalho restrito a essas datas torna-se superficial, já que não contempla a maior parte do que deve ser ensinado. Segundo Munsberg (2020), predominam, no Brasil, propostas pedagógicas na perspectiva da educação monocultural colonizadora, fundamentadas nos pressupostos da racionalidade hegemônica moderna/colonial/eurocentrada, com currículos descontextualizados. Em relação ao que se deve ensinar aos nossos alunos, quanto ao passado dos povos indígenas e africanos nesses cinco séculos de presença europeia do Brasil, acreditamos ser importante pensar em como se produziram essas "histórias", como se constituíram essas culturas, para que possamos refletir e construir uma educação antirracista.

Em 2003, o movimento negro conseguiu a conquista de se inserir oficialmente no currículo escolar através da lei 10.639/2003 (BRASIL, 2003) que tornou obrigatório, nos estabelecimentos de ensino fundamental e médio, o ensino sobre a História e a Cultura Africana e Afro-brasileira nas disciplinas de Educação Artística, Literatura e História.

No ano de 2008, essa legislação foi modificada e tornou-se a lei $11.645 / 2008$ (BRASIL, 2008) que instituiu a obrigatoriedade, nos estabelecimentos de ensino fundamental e médio, do ensino sobre a História e a Cultura Afro-brasileira e Indígena nas disciplinas de Educação Artística, Literatura e História. Ambas as leis foram uma conquista, a partir da pressão dos movimentos negro e indígena, para que suas histórias fossem contadas e suas culturas abordadas de forma adequada. Sua importância fundamental, ao estimular a atualização e adequação dos livros didáticos, a busca por materiais que abordem as temáticas de forma mais séria e propiciem um maior aprofundamento das questões afro e indígena, que muitas vezes eram silenciadas ou retratadas de forma superficial e até mesmo folclórica. Ambas as leis dão visibilidade para a história desses povos que são pouco reconhecidos pela população em geral, em razão de só aprenderem na escola não indígena a História Brasileira a partir da visão do colonizador e pelo fato de as temáticas afro-brasileira e indígena serem ensinadas, grande parte das vezes, a título de data comemorativa, sem aprofundamento, tratando as culturas de forma genérica e estereotipada.

Outro ponto positivo, referente às leis, é que elas estimulam pesquisas em relação às temáticas afro-brasileira e indígena, pressionando para que esse conteúdo 
GOMES, L. B.; FLORES, C. G. da S.; SILVA, G. F. da; CASAGRANDE, C. A.

seja incluído nos cursos de licenciatura. Porém, por não ter obrigatoriedade no currículo do Ensino Superior, muitos cursos inserem essas disciplinas como optativas. Dessa maneira, diversos docentes se formam sem o conhecimento necessário para trabalhar com o tema. É importante salientar que a aplicação de práticas que contemplem as exigências previstas nas leis requer um projeto de formação e capacitação do docente. Não basta exigir que o professor ensine algo para o qual não tem preparo prévio, pois isso pode resultar na reprodução, cada vez maior, de culturas e identidades estereotipadas.

A Base Nacional Comum Curricular - BNCC (Brasil, 2017) foi implementada nas escolas entre 2019 e 2020 (a implementação se deu em etapas). Nos anos iniciais do Ensino Fundamental, a BNCC trouxe novidades positivas em relação às questões afrobrasileira e indígena, especialmente no $4^{\circ}$ e $5^{\circ}$ ano do Ensino Fundamental, com uma abordagem mais adequada e aprofundada, relacionando as disciplinas de História, Geografia, Artes e Ensino Religioso. Esses níveis estudam o estado e o país e, a partir disso, veem a composição do território, as movimentações dos povos presentes antes, durante e após a colonização, mitos de criação, espiritualidade, cidadania e conquista de direitos, entre outros.

Entretanto, ao observarmos a disciplina de História ${ }^{10}$ no mesmo documento nos anos finais do Ensino Fundamental, percebemos uma matriz fortemente eurocentrada, que aborda as temáticas indígena e afro-brasileira com grandes lacunas, quase que como enxertos. No $6^{\circ}$ ano, é trabalhado o eixo da antiguidade, apresentando a África somente a partir do Egito e os indígenas em relação ao povoamento da América, após isso há uma lacuna temporal e o enfoque se volta para os povos Inca, Maia e Asteca, desconsiderando toda a diversidade contida nos povos africanos e ameríndios. Já no 70 ano, aborda-se o eixo da modernidade apresentando a história dos povos ameríndios e africanos a partir do processo de colonização e da escravidão. No $8^{\circ}$ ano o eixo é o iluminismo, a BNCC mantém o enfoque desde o âmbito da colonização e depois dá um salto no tempo para discutir a tutela, que foi um sistema que visava à assimilação e à aculturação dos afro-brasileiros e indígenas. Na sequência, há mais uma lacuna temporal e o documento segue falando sobre ações afirmativas e discursos civilizatórios. Por fim, no $9^{\circ}$ ano, é abordada a idade contemporânea que propõe a discussão sobre o processo de colonização e sobre a importância da Constituição Federal de 1988 no que diz respeito aos direitos dos afro-brasileiros e povos indígenas.

Analisando as Ciências Humanas e Sociais da BNCC no Ensino Médio, percebemos uma postura generalista, eurocentrada e focada no sistema capitalista. As temáticas afro-brasileira e ameríndia aparecem somente em relação às políticas públicas voltadas a essa parcela da população, como podemos perceber na única habilidade que trata de ambos nesse documento, apresentada a seguir: "Relacionar as demandas políticas, sociais e culturais de indígenas e afrodescendentes no Brasil contemporâneo aos processos históricos das Américas e ao contexto de exclusão e inclusão precária desses grupos na ordem social e econômica atual" (BRASIL, 2017). Logo, podemos concluir que o currículo da Educação Básica segue uma matriz eurocêntrica, abordando as questões afro-brasileira e indígena de forma superficial e descontextualizada. A consequência disso é a reprodução de estereótipos que perpetuam preconceitos e invisibilidades. As práticas escolares buscam suas bases teóricas em uma academia que 
valoriza e reproduz o pensamento epistemológico eurocentrado, baseado nos autores, na estética, nas crenças, nos modos de ser e viver importados dos países europeus.

Segundo Adichie (2019), se começarmos a contar a história com as flechas dos indígenas americanos, e não com a chegada dos britânicos, ela será completamente diferente. Se iniciarmos com o fracasso do Estado africano, e não com a criação colonial do Estado africano, a história será completamente diferente. O que se coloca como necessidade epistêmica de construção é um pensamento que se nutre por outras fontes, que se ampara na construção de um saber que não se reduz ao ocidental colonizador, mas que aposta e aponta para um horizonte de sentido construído onde o que ganha importância é a defesa da vida e, portanto, é uma aposta na garantia da diversidade como um princípio de respeito às existencialidades.

Diante do exposto, é possível perceber que o ponto de vista do qual parte o currículo escolar perpetua a visão do colonizador acerca da nossa história, ou seja, a escola conta uma história única, a pequena história. Isso se mostra, por exemplo, em Gomes, Silva e Casagrande (2020), a partir da análise das imagens dos indígenas nos livros didáticos contemporâneos: os autores perceberam que a imagem do índio que ainda é reproduzida na escola é, geralmente, a do bom selvagem que se pinta, caça, realiza rituais, vive em ocas, cuida da natureza ou a do ameríndio selvagem e ameaçador. Os autores percebem que também há a tendência da reprodução da figura do ameríndio vinculada ao passado, dando uma ideia de descontinuidade na existência dos povos indígenas ou passando a visão de que os que se encontram na cidade não são mais índios, essa invisibilidade se deve ao fato de não os reconhecerem por estarem idealizando uma certa visão a respeito destes.

Por esse motivo, é necessário fazer o giro epistêmico, trazer para dentro da escola a grande história e abrir espaço para a interculturalidade, autoaceitação, autoidentificação e autorreconhecimento.

\section{A IMPORTÂNCIA DE CONTAR MUITAS HISTÓRIAS}

Até aqui sustentamos o argumento de que a história que conhecemos ou que, pelo menos, a história reconhecida como oficial pode ser analisada a partir dos conceitos de pequena história (KUSCH, 1999) ou de história única (ADICHIE, 2019). Apesar de serem diferentes, os conceitos de pequena história e de história única se complementam na medida em que somente uma versão é contemplada e aceita. No entanto, apesar de silenciadas, existem outras narrativas que permanecem vivas, seja na memória ancestral, nos saberes sagrados, nas manifestações culturais ou nos movimentos populares; estas fazem parte da grande história e demonstram a pluralidade que constitui nosso país. Como afirma Mignolo (2008, p. 291), "Na América do Sul, na América Central e no Caribe, o pensamento descolonial vive nas mentes e corpos de indígenas bem como nas de afrodescendentes".

A colonização nos deixou marcas profundas, mas não apagou nossa ancestralidade, já que ela possui raízes profundas. Segundo Munduruku (2009), somos a continuação de um fio que nasceu muito tempo atrás, vindo de outros lugares, iniciado por outras pessoas, completado, remendado, costurado e continuado por nós. De uma 
GOMES, L. B.; FLORES, C. G. da S.; SILVA, G. F. da; CASAGRANDE, C. A.

forma bem mais simples, poderíamos dizer que temos uma ancestralidade, um passado, uma tradição que precisa ser continuada, costurada, bricolada todo dia. A ancestralidade aqui se refere não somente aos nossos antepassados e à nossa descendência, mas a um passado anterior a nós, que resiste e integra parte do que somos. Uma ancestralidade americana que mistura crenças, cores, culturas, histórias, línguas, entre outros aspectos. Um conhecimento que muitas vezes é negado ao estudante quando abordamos a história única do colonizador, a pequena história, desconsiderando as demais etnias que nos constituíram enquanto indivíduos americanos.

Não precisamos permanecer em uma constante busca para nos encaixarmos no modelo do colonizador, um homem branco, heterossexual, cristão, capitalista e europeu; antes disso, precisamos reconhecer que não existe apenas uma única forma de ser humano. Para que esse reconhecimento seja possível, é preciso que haja um processo de sensibilização e de abertura para o novo, em um projeto intenso de primeiramente des-aprender, para, por fim, re-aprender. Faz-se necessário um movimento de "giro epistêmico e decolonial" e, portanto, "geoepistêmico". É importante dizer que o giro geoepistêmico só é possível a partir de propostas que tenham a intenção de potencializar a diversidade, a diferença e esse outro que foi silenciado, esquecido ou arremessado para fora da história "oficial". Nesse sentido, a perspectiva da interculturalidade, via práticas no campo da educação, torna viável a construção de projetos de intervenção e de transformação social, cultural e educativa. A interculturalidade parte de onde se está e com quem se está (geoepistêmico) para a construção do diálogo, para a escuta e para dar início aos processos de des-aprender.

Colocar-se na dinâmica de des-aprender e re-aprender implica assumir uma postura política de reflexão e questionamento em relação ao conhecimento. Acompanhando as indagações de Grada Kilomba ${ }^{11}$ (2019, p. 50) sobre o conhecimento dito oficial, ela questiona: "De quem é esse conhecimento? Quem é reconhecido(a) como alguém que possui conhecimento? E quem não o é? [...] quem está no centro? $\mathrm{E}$ quem permanece fora, nas margens?". Ao nos permitirmos realizar essas perguntas, deslocamos o interesse para um foco e com isso acabamos idenficando-o e nominandoo, ao fazer isso torna-se ciente e consciente de onde se localiza o "centro" que emana e "norteia" como devem funcionar as lógicas das relações, que tão bem se fazem presentes no espaço acadêmico e se replicam como resultado dessas relações para outros espaços, como é o território da Educação Básica, por exemplo.

As histórias continuam sendo contadas desde um único ponto de vista. $\mathrm{O}$ ingresso de outras perspectivas, desse mesmo ponto, carecem de modos mais incisivos de investimentos, de estratégias mais potentes e de ações muito mais aguerridas do que simplesmente a produção de um discurso que se ampara na racionalidade ocidental, ou seja, o rendimento a um modo de pensar e, por dentro desse modo, a procura por outros caminhos. Haveria de se "beber epistemicamente em outras fontes", portanto, abrindo espaço para a possibilidade de construção de uma geoepistemologia. Sobre o que foi dito anteriormente, $\operatorname{Krenak}^{12}$ (2019, p. 24) lembra que "precisamos ser críticos com essa ideia plasmada de humanidade homogênea", a ideia de uma única humanidade é equivocada já que há pluralidade, modos diferentes de existir e cosmovisões distintas. Conforme Krenak (2019), a ideia de que os brancos europeus podiam sair colonizando o resto do mundo estava sustentada na premissa de que havia uma humanidade esclarecida que precisava ir ao encontro da humanidade obscurecida, 
trazendo-a para essa luz incrível. A ideia trazida pelo autor mostra que esse ato de "civilizar" tinha como pressuposto que havia uma forma correta de se viver na Terra. Esse pensamento guiou por muitos séculos as empreitadas colonizadoras ao longo da história, tanto é que ainda vemos presentes elementos da colonialidade em nossa sociedade.

Em entrevista concedida ao jornalista Thiago Amâncio (2020), Krenak propõe, ao falar sobre o livro "Ideias para adiar o fim do mundo", uma outra experiência chamada "florestania", que seria a construção de espaços de convivência, criação e reprodução da cultura em termos de povos que vivem em relação com a natureza, na floresta. Pensando nisso, a própria noção de "florestania" mostra-se disruptiva, se contrapondo a de cidadania, aprisionada à cidade de cimento, propondo uma vida ativa e participativa onde haja a relação de respeito com a natureza.

De acordo com Dussel (2016, p. 51), "as culturas periféricas foram colonizadas, excluídas, desprezadas, negadas e ignoradas pela Modernidade eurocentrada, porém, não foram eliminadas", elas sobreviveram em silêncio e atualmente estão renascendo das cinzas da colonização. Aquilo que tão sabiamente a intelectual indiana Gayatri Chakravorty Spivak (2018) asseverou ao dizer que "os outros", que não compuseram a oficialidade da história do colonizador, ou aqueles que ocuparam o lugar de colonizados, dominados, escravizados, na verdade não ficaram à margem da história, mas foram arremessados para fora dela. Assim, percebemos dois passos importantes a serem dados na perspectiva de uma educação decolonial, o primeiro é no sentido de compreender a crueldade do processo de colonização e as relações de exploração e domínio da colonialidade. O segundo passo é em direção à autovalorização, ou seja, buscar a origem positiva de nossa própria tradição cultural (DUSSEL, 2016).

Nesse sentido, entendemos que o movimento de decolonialidade na Educação deve estar presente desde sua base, isto é, desde a Educação Básica. Conforme Munduruku (2019), a escola "entorta" o pensamento da criança à medida que a coloca em uma forma cultural e a torna um ente igual a todos os outros. O autor propõe que haja uma "pedagogia do desentortamento do pensamento", já que o pensamento "torto", que o ocidental tem praticado, criou muitas gerações de gente descomprometida, que cresceu egoísta e masoquista. Para isso, é preciso "desentortar o pensamento", des-aprender esse modo ocidental de ser humano, apontando um único caminho, e re-aprender com o conhecimento ancestral modos outros de existir reexistindo.

Partindo dessa perspectiva, pensamos a escola como um espaço privilegiado para o "desentortamento do pensamento", o conhecimento da grande história, o questionamento da ideia de história, cultura e estética únicas, realizando uma abertura ao diálogo intercultural. Para Walsh (2010), a educação intercultural só tem impacto e valor quando é assumida de forma crítica, ou seja, como uma atitude pedagógica que tenha como objetivo mudar as estruturas da sociedade, aquelas que racionalizam, desumanizam e inferiorizam parte da população. Nessa perspectiva, a interculturalidade não se limita a "tolerar" as diferenças, antes disso promove relação "entre" os diferentes. A educação na perspectiva intercultural ensina a "aprender a ser, estar e (con)viver com o outro" (MUNSBERG; SILVA, 2018, p. 148). Dessa forma, defendemos a sala de aula como 
GOMES, L. B.; FLORES, C. G. da S.; SILVA, G. F. da; CASAGRANDE, C. A.

um local onde as mais variadas histórias sejam compartilhadas para que possamos iniciar o enfrentamento da colonialidade e de todas suas formas de opressão e empobrecimento de nossa cultura. Assim como Ailton Krenak acreditamos que "há centenas de narrativas de povos que estão vivos, contam histórias, cantam, viajam, conversam e nos ensinam mais do que aprendemos nessa humanidade" (KRENAK, 2019, p. 30).

\section{CONSIDERAÇÕES FINAIS}

O conhecimento da história na perspectiva dos povos que passaram pelo processo de colonização é o primeiro movimento do giro decolonial, e somente a partir dele é possível tomar consciência de todo horror e luta que envolveu o projeto colonial europeu. A luta contra todas as formas de opressão e exploração da colonialidade perpassa a reflexão crítica acerca de nosso passado. A grande história, a história que compreende os povos originários do Brasil, precisa fazer parte efetivamente do currículo escolar desde a Educação Básica. O olhar positivo para nossa ancestralidade é outro passo importante. Como esses povos resistiram e continuam a opor-se ao projeto colonial? Que conhecimentos possuem esses povos? Como eles constroem suas narrativas sobre o mundo? Qual a relação desses povos com o tempo? Quais são seus conhecimentos acerca do divino? Afinal, o que a pequena história e todos os estereótipos da história única nos omitiram?

A escola intercultural é aquela onde muitas histórias são contadas e valorizadas, onde há espaço para ouvir vozes-outras e conhecer narrativas para além da história dita oficial. É um lugar onde a história única, seus estereótipos e sua estética são questionadas. Um espaço crítico, onde se busca destruir as estruturas sociais e raciais construídas pela colonialidade. Infelizmente, o estudo realizado não permite afirmar que estamos dando passos largos nessa direção, mas permite apontar possibilidades que se abrem como novos horizontes. Há um trabalho árduo a ser feito, envolvendo desde a criação de políticas públicas até o estabelecimento de ações inspiradoras para uma educação que faça sentido desde onde e com quem se está.

Um projeto de escola intercultural pode ser uma dessas possibilidades de ampliar horizontes, experimentando ações com os professores como sujeitos ativos e atuantes, sensibilizando-se ao serem sensibilizados por uma outra forma de contar a grande história que contempla a todos e todas. Isso necessariamente implica a formação docente que permita o acesso, construção e valorização de conhecimentos historicamente "arremessados para fora da história". Acima de tudo, o professor precisa "aprender a desaprender", necessita da "pedagogia do desentortamento do pensamento", afinal aprendemos uma história única, mas não podemos continuar perpetuando-a. 


\section{FOR AN INTERCULTURAL SCHOOL: CLASSROOM A PLACE FOR MANY STORIES}

ABSTRACT:The article addresses coloniality in Basic Education and aims to discuss how the Brazilian school system has joined the reproduction of the Eurocentric historical perspective. For this purpose, it establishes a hermeneutical dialogue from concepts and reflections of decolonial authors, who defend a south based thinking production. We recommend the decolonial pedagogy to reach other learnings, narratives and cosmovision. Such dynamic implies a critical dialogue about knowledge, western ways of thinking, and an openness for indigenous and afro diasporic people in American lands. In the end, we defend a proposal of intercultural education, based on the plurality and ancestry of the people.

KEYWORDS: Coloniality. Decolonial Education. Intercultural Education. Geoepistemology.

PARA UNA ESCUELA INTERCULTURAL: EL AULA COMO LUGAR DE MUCHAS HISTORIAS

RESUMEN: El artículo aborda el tema de la colonialidad en la Educación Básica y tiene como objetivo discutir la forma en que la escuela brasileña ha participado en la reproducción de una perspectiva histórica única, la eurocéntrica. Para ello, establece un diálogo hermenéutico basado en conceptos y reflexiones de autores decoloniales, que defienden la producción del pensamiento desde el sur. Se sugiere la pedagogía decolonial como una de las formas de llegar a otros conocimientos, narrativas y visiones del mundo. Dicha dinámica implica un diálogo crítico sobre conocimientos, formas de pensar en el mundo occidental y una apertura a los pueblos indígenas y afro-diaspóricos en tierras americanas. Finalmente, se defiende la propuesta de una educación intercultural, que tenga como base la pluralidad y la ancestralidad de sus pueblos.

PALABRAS CLAVE: Colonialidad. Educación Descolonial. Educación Intercultural. Geoepistemologia

\section{NOTAS}

1 - É importante diferenciar os conceitos de "decolonial" e "descolonial". O termo "descolonial" indica o esforço para superar colonialismo. Em contrapartida, o termo "decolonial" carrega um sentido mais radical, pois procura transcender a colonialidade, enquanto herança do colonialismo. Dessa maneira, o termo decolonial implica uma crítica contínua à face obscura da modernidade, que continua operando até hoje por meio de uma estrutura de poder colonial.

2 - Rodolfo Kusch foi filósofo, ensaísta, professor e pesquisador. Nascido em Buenos Aires, dedicou-se ao estudo do pensamento popular e indígena na América Profunda. As informações sobre a biografia de Rodolfo Kusch constam em Gerónimo e Tasat (2020). 
GOMES, L. B.; FLORES, C. G. da S.; SILVA, G. F. da; CASAGRANDE, C. A.

3 - A diferenciação entre a pequena e a grande história consta no livro América Profunda, presente no Tomo Il das Obras Completas (KUSCH, 1999).

4 - Para a concepção decolonial, houve uma conquista ou uma invasão e não uma descoberta.

5 - Daniel Munduruku, graduado em Filosofia, tem licenciatura em História e Psicologia. É Doutor em Educação pela USP e pós-doutor em Linguística pela Universidade Federal de São Carlos UFSCar. É diretor presidente do Instituto UKA - Casa dos Saberes Ancestrais. Suas obras são vencedoras de vários prêmios, inspiram e encantam muitas crianças, jovens e adultos.

6 - Djamila Taís Ribeiro dos Santos é uma filósofa, feminista negra, escritora e acadêmica brasileira. É pesquisadora e mestra em Filosofia Política pela Universidade Federal de São Paulo (Unifesp).

7 - Chimamanda Ngozi Adichie estudou Comunicação e Ciências Políticas na Universidade de Connecticut nos Estados Unidos da América. Realizou mestrado em Escrita Criativa na Universidade Johns Hopkins de Baltimore e mestrado em Estudos Africanos pela Universidade de Yale.

8 - Linda Tihuwai Smith é uma intelectual indígena Maori da Nova Zelândia. É professora na Universidade de Waikato, em Hamilton, Nova Zelândia e se autodeclara Ngāti Awa, Ngāti Porou. Se destaca mundialmente em virtude dos Estudos Indígenas e da Educação Indígena, bem como da pesquisa Kaupapa Maori (abordagem teórico-metodológica).

9 - No ano de 2020, o governo em vigência comemorou o dia 13 de maio, data alusiva à abolição da escravatura. Esse fato desconsidera a luta do movimento negro, que celebra o dia da Consciência Negra em 20 de novembro, data que relembra a morte de Zumbi dos Palmares. Essa atitude é um exemplo da atualidade desse debate, pois demonstra a forma como os governos podem contribuir para a perpetuação da pequena história em detrimento da grande história.

10 - Aqui elegemos a disciplina de História para mostrar a forma como as diferentes culturas indígenas e africanas são abordadas no currículo escolar. Vale ressaltar que, de acordo com as leis 10.639 (Brasil, 2003) e 11.645 (Brasil, 2008), o currículo escolar da Educação Básica deve abordar a história e a cultura afro-brasileira e indígena nas disciplinas de História, Educação Artística e Literatura.

11 - Grada Kilomba é uma escritora, teórica e artista que ativa e produz saber decolonial ao tecer relações entre gênero, raça e classe. Sua obra dispõe de formatos e registros distintos, como publicações, leituras encenadas, performances-palestras, videoinstalações e textos teóricos, criando um espaço híbrido entre conhecimento acadêmico e prática artística.

12 - Ailton Alves Lacerda Krenak é um líder indígena brasileiro, nascido na região do Vale do Rio Doce, ambientalista e escritor brasileiro. É considerado uma das maiores lideranças do movimento indígena brasileiro, possuindo reconhecimento internacional. Pertence a etnia indígena Krenak.

\section{REFERÊNCIAS}

ADICHIE, C. N. O perigo de uma história única. São Paulo: Companhia das Letras, 2019. 
AMÂNCIO, T. É preciso adiar o fim do mundo para contar mais história, diz autor indígena.Zero Hora, Porto Alegre, 13 de julho de 2019.Cultura. Disponível em: https://gauchazh.clicrbs.com.br/cultura-e-lazer/noticia/2019/07/e-preciso-adiar-o-fimdo-mundo-para-contar-mais-historia-diz-autor-indigenacjy1p8dwy01df01nj04p31147.html. Acesso em: 22 de julho de 2020.

BALLESTRIN, L. América Latina e o giro decolonial. Revista Brasileira de Ciência Política, no11. Brasília, maio - agosto de 2013, pp. 89-117. Disponível em http://www.scielo.br/pdf/rbcpol/n11/04.pdf. Acesso em 14 jun. 2020.

BONIN, I. T. Com quais palavras se narra a vida indígena na literatura infanto-juvenil que chega às escolas? In: SILVEIRA, R. H. (Org.). Estudos culturais para professor@s. Canoas: Editora da Ulbra, 2008.

BRASIL. Lei no 11.645/2008, de 10 de março de 2008. Estabelece as diretrizes e bases da educação nacional, para incluir no currículo oficial da rede de ensino a obrigatoriedade da temática "História e Cultura Afro-Brasileira e Indígena". Brasília, DF, 2010.

BRASIL. Base Nacional Comum Curricular. Brasília: MEC, 2017. Disponível em: http://basenacionalcomum.mec.gov.br/images/BNC C_20dez_site.pdf. Acesso em: 22 dez. 2017.

BRASIL. Lei $n^{\circ} 10.639$, de 9 de janeiro de 2003. Altera a lei $n^{\circ} 9.394$, de 20 de dezembro de 1996, que estabelece as diretrizes e bases da educação nacional, para incluir no currículo oficial da rede de ensino a obrigatoriedade da temática "História e Cultura Afrobrasileira", e dá outras providências. Disponível em: http://www.planalto.gov.br/ccivil_03/leis/2003//10.639.htm. Acesso em: 12 ago. 2020.

DUSSEL, E. Transmodernidade e interculturalidade: interpretação a partir da filosofia da libertação. Sociedade e Estado, n 1. Brasília, janeiro - abril de 2016, p. 51-73.

FONTOURA. F. P. Autor: MENDANHA, J. J. Compositor. Hino do Rio Grande do Sul. [S. I.: s. n.], 1966. Disponível em: https://www.letras.mus.br/hinos-de-estados/126618/. Acesso em: 12 ago. 2020.

GERÓNIMO, F.; TASAT, J. A. Acerca de Rodolfo Kusch. In:TASAT, J. A. et al. Rodolfo Kusch: Geocultura de un hombre americano. Chile: Universidad de la Serena; México: CRESUR, 2020.

GOMES, L. B., SILVA, D. R. Q., \& CASAGRANDE, C. A. (2020). A representação dos povos indígenas contemporâneos nos livros didáticos. Arquivos Analíticos de Políticas Educativas, 28(75). https://doi.org/10.14507/epaa.28.4754 Este artigo faz parte do dossiê especial, Educação e Povos Indígenas - Identidades em Construção e Reconstrução, editado por Juliane Angnes e Kaizo Iwakami Beltrao. 
GOMES, L. B.; FLORES, C. G. da S.; SILVA, G. F. da; CASAGRANDE, C. A.

HISTÓRIAS para ninar gente grande. Compositores: MIRANDA, T.; OLIVEIRA, R.; BOLA, M., MAMÁ; DOMÊNICO, D.; FIRMINO, D. Samba-Enredo 2019 - G.R.E.S. Estação Primeira de Mangueira. Rio de Janeiro, 2019. Disponível em: https://www.letras.mus.br/manqueirarj/samba-enredo-2019-historias-para-ninar-gente-grande/. Acesso em: 07 jun. 2020.

KRENAK, A. Ideias para adiar o fim do mundo. São Paulo: Companhia das letras, 2019.

KUSCH, R. Obras completas, Tomo II. Santa Fé, Argentina: Fundación Ross, 1999.

MIGNOLO, W. D. Desobediência Epistêmica: a opção descolonial e o significado de identidade em Política. Cadernos de Letras da UFF. No 34, p. 287-324, 2008.

MIGNOLO, W. D. El pensamiento decolonial: desprendimiento y apertura. Un manifiesto. In: CASTRO-GÓMEZ, S.; GROSFOGUEL, R. El giro decolonial. Reflexiones para una diversidad epistémica más allá del capitalismo global. Bogotá: Siglo del Hombre Editores; Universidad Central, Instituto de Estudios Sociales Contemporáneos y Pontificia Universidad Javeriana, Instituto Pensar, 2007. p. 25-45. Disponível em: http://www.unsa.edu.ar/histocat/hamoderna/grosfoguelcastrogomez.pdf. Acesso em: 10 jul. 2020.

MUNDURUKU, D. O banquete dos deuses: conversa sobre a origem da cultura brasileira. São Paulo: Global, 2009.

MUNDURUKU, D. Das coisas que aprendi: ensaios sobre o bem-viver. Lorena: DM Projetos Especiais, 2019.

MUNSBERG, J. A. S.; FERREIRA DA SILVA, G. Interculturalidade na perspectiva da descolonialidade: possibilidades via educação. Revista Ibero-Americana de Estudos em Educação, Araraquara, v. 13, n. 1, p. 140-154, jan./mar., 2018.

MUNSBERG, J. A. S. Por uma proposta pedagógica na perspectiva da educação intercultural decolonizadora. Orientador: Gilberto Ferreira da Silva. - 2020. $138 \mathrm{f}$. Tese (Doutorado) - Universidade La Salle. Programa de Pós-Graduação em Educação, 2020, Canoas, BR-RS.

ORLANDI, E. P. Terra à vista: discurso do confronto: velho e novo mundo. Campinas: Editora Unicamp, 1990.

QUIJANO, A. Colonialidad, poder, globalización e democracia. Novos Rumos, Ano 17, no 37, p. 4-28. 2002.

KILOMBA, G. Memórias da plantação. Episódios do racismo cotidiano. Rio de Janeiro, Cobocó, 2019.

RIBEIRO, D. Pequeno manual antirracista. São Paulo: Companhia das Letras, 2019. 
SALAINI, C. J.; CARVALHO, A. P. C. Memória, mídia e imaginário social: o caso Porongos. Ilha Revista de Antropologia, Florianópolis, v. 10, n. 2, p. 155-173, dez. 2008. ISSN 2175-8034. Disponível em: https://periodicos.ufsc.br/index.php/ilha/article/view/2175-8034.2008v10n2p155/15995. Acesso em: 09 ago. 2020. doi: https SMITH, L. T. Descolonizando metodologias: pesquisa e povos indígenas. (trad. Roberto G. Barbosa). Curitiba: Editora UFPR, 2018.

SPIVAK, G. C. Pode o subalterno falar? Belo Horizonte: Editora da UFMG, 2018.

WALSH, C. Introducion - (Re) pensamiento crítico y (de) colonialidad. In: WALSH, C. Pensamiento crítico y matriz (de)colonial. Reflexiones latinoamericanas. Quito: Ediciones Abya-yala, 2005. p. 13-35.://doi.org/10.5007/2175-8034.2008v10n2p155.

LuANa BARTH Gomes: Doutoranda em Educação pela Universidade La Salle/Canoas com bolsa CAPES/PROSUC. Professora dos Anos Iniciais do Ensino Fundamental.

Orcid: http://orcid.org/0000-0002-3598-1772

E-mail: luanabarth@yahoo.com.br

Cristine Gabriela de Campos Flores: Doutoranda em Educação pela Universidade La Salle/Canoas com bolsa FAPERGS de dedicação exclusiva.

Orcid: https://orcid.org/0000-0001-9336-8557

E-mail: cristinegabriela@smail.com

Gilberto Ferreira da Silva: Doutor em Educação. Professor do Programa de Pósgraduação em Educação da Universidade La Salle/Canoas. Líder do Grupo de Pesquisa em Educação Intercultural (GPEI).

Orcid: https://orcid.org/0000-0002-6294-2322

E-mail: gilberto.ferreira65@gmail.com

Cledes Antonio Casagrande: Doutor em Educação pela PUCRS. Professor do Programa de Pós-graduação em Educação da Universidade La Salle.

Orcid:http://orcid.org/0000-0003-1499-1661

E-mail: cledes.casagrande@unilasalle.edu.br

Este periódico utiliza a licença Creative Commons Attribution 3.0, para periódicos de acesso aberto (Open Archives Iniciative - OAI). 